\title{
Uma análise das objeções ao conceito de professor reflexivo em ensino de ciências na educação básica paulista
}

\author{
Analysis of the objections to the concept of reflective teacher in science \\ education, in the public school of São Paulo
}

Airton Acácio Castilho Christófalo - Universidade Estadual Paulista "Julio de Mesquita Filho" (FAAC/UNESP) | Bauru | SP | Brasil | E-mail: airtonch@gmail.com

José Roberto Boettger Giardinetto - Universidade Estadual Paulista "Julio de Mesquita Filho" (FAAC/UNESP) | Bauru | SP | Brasil | E-mail: airtonch@gmail.com

Resumo: Este artigo parte da questão formulada durante a realização da pesquisa de mestrado no ensino de ciências, sobre a consistência da contextualização das estratégias de ensino menos conteudistas, mais focadas em debates e ações diversificadas, cuja análise se atenta aos ideários presentes em autores de fundamento construtivista humano, contemplando nomes reconhecidos em concursos de admissão de professores da educação básica, e nos documentos oficiais da educação, como PCN(s), o currículo oficial do estado de São Paulo, cursos de licenciatura e pós-graduação, que se apresentam em seus pressupostos, matrizes de trabalho conhecidos como "professor reflexivo". Propõe este excerto, pontuar algumas das suas objeções, principalmente a partir de um contraposto em revisão de pesquisas, expondo uma síntese de resultados contraditórios de tais pressupostos.

Palavras-chave: Ensino de ciências. Professor reflexivo. Ensino básico.

Abstract: This paper is formulate on the question proposed in post graduate research in science education, and about the consistency of authors in the contextualization of practices in teaching and learning strategies in human-constructivist views in science education. The authors of basic educations reflexive practices presents in official publications in education such as PCN(s) and proposte Curricular in the state São Paulo, the undergraduate and graduate courses, which present themselves in their assumptions, "reflexive teachers". Propose in this research there, to point out some of their objections, mainly from a counterpoint in review of research, exposing a synthesis of contradictory results of such assumptions.

Keywords: Teaching in science. Reflexive teacher. Basic education.

DOI: http://dx.doi.org/10.22484/2177-5788.2018v44n1p133-153

Recebido em abril 2018. $\quad$ Aprovado em maio de 2018. 


\section{Introdução}

Desde meados de 1990, as referências progressistas no ensino salientam que a formação educacional básica se depara com certas dificuldades em se atingir um dos seus objetivos essenciais que é de formar um cidadão crítico e com uma base de conhecimento científico e matemático, pois, conforme identifica Mintzes et al. (1998), a realidade do ensino revela fragilidades em termos de domínios conceituais e contextos de aplicação que são itens necessários na capacitação humana para formar alunos com opiniões sobre os assuntos corriqueiros, com autonomia e propriedade em utilizar os conhecimentos escolares no dia a dia, para além das aprovações em vestibular. Identifica-se a necessidade do pensar sobre a formação de ensino básico, pois existe um caminho que perpassa os fundamentos regimentais de diferentes documentos oficiais que regulam as relações de Ensino e Aprendizagem, assim como da Formação de Professores que Ensinam Ciências e Matemática, dentre eles, os Parâmetros Curriculares Nacionais (PCN e PCN+) e cadernos de referência das matrizes de competências do currículo paulista. Pesquisadores da área de Ensino de Ciências, como Cachapuz et al. (2005) e Carvalho e Gil-Perez (2009), também tecem críticas e considerações importantes referentes à situação atual da Educação em Ciências () bem como apresentam propostas que muitas vezes não chegam à sala de aula. Referindo-se à Educação em Ciências, Neves (1998, p. 74) destaca "O que temos visto nas últimas décadas é a ciência sendo apreendida como um dado e não como uma possibilidade de construção e integração com as demais Ciências e com as necessidades diárias do cidadão comum".

O fundamento das teses progressistas iniciadas nos anos de 1990 apresenta no seu desenvolvimento falhas estruturais, algumas delas evidenciadas nas concepções de indivíduo e da realidade que se apoiam. Pretende-se realizar neste artigo, uma revisão e análise de aspectos 
teóricos que se definem pela ênfase na formação de professores e a investigação dos procedimentos de ensino, objeto este que ora se examina, e se considera também como um motivo ideológico, segundo Facci (2004), a concentração das fragilidades do ensino básico em torno do trabalho do professor. Cabe destacar que este não é o único ou principal determinante das fragilidades existentes no ensino, pois, muitas dessas fragilidades se concentram na estrutura social existente, como o distanciamento institucional da escola, dos itens de qualidade de vida e cunho social, subsidiadores das condições propícias de aprendizado.

A partir das considerações realizadas, o presente excerto pretende mostrar a existência de certa ideologia em considerar por demasia a ênfase com que os autores do artigo identificam como "retórica sobre a qualidade da formação do professor" e as suas estratégias do "ensinar", especialmente pelo fato de muitos autores se fixarem na discussão teórica e metodológica que menospreza aspectos sobre a realidade social, centrando-se quase exclusivamente na figura do professor e de elementos sobre a qualidade da sua formação, para tanto ressaltam-se as análises de Duarte (2001) e Giardinetto (2000) sobre os propósitos da teoria reflexiva.

Um dado inequívoco é sem dúvidas, o fato de este assunto perpassar, necessariamente pela formação de professores e isso implica discutir, à luz das pesquisas já realizadas, o papel das disciplinas didáticas e metodológicas presentes na estrutura curricular dos cursos de licenciatura. Essas disciplinas oportunizam aos alunos de licenciatura, por meio dos estágios supervisionados, ricas experiências didáticas. Neste período, notam os autores da pesquisa que, conforme Camargo e Nardi (2004), os cursos de licenciatura têm passado por um processo de reestruturação a partir de 2002. 
No ano de 2002, as Diretrizes Curriculares Nacionais para a Formação de Professores de Educação Básica ${ }^{1}$ foram aprovadas pelo Conselho Nacional de Educação, dentre as de diversos outros cursos, entre elas as Diretrizes Curriculares Nacionais para os Cursos de Física². Esse fato levou os conselhos de cursos de graduação de todo o país a se preocuparem com a reestruturação de seus projetos, segundo Camargo et al. (2012). O primeiro documento propõe que o perfil do licenciando, futuro professor, deve ser estabelecido desde o início do curso, tendo como eixo norteador disciplinas integradoras, como as chamadas "práticas de ensino como componentes curriculares" e o "estágio supervisionado", que acontece preferencialmente no ambiente escolar, articulado com o campo de atuação do futuro professor: a escola de educação básica. Alguns cursos de licenciatura em Física após o processo de reformulação procuraram inserir em suas estruturas curriculares abordagens oriundas de resultados da Pesquisa da área de Educação em Ciências e Matemática, como por exemplo, Ciência, Tecnologia, Sociedade e Ambiente; da História e Filosofia da Ciência; da Resolução de Problemas; das Tecnologias e Novas Abordagens e Linguagem e Cognição. Ações que objetivam um ensino mais significativo, tanto para os alunos como para os professores, segundo Cachapuz et al. (2005), promovendo uma formação científica que leve os cidadãos participar na tomada de decisões, em assuntos que envolvam ciência e tecnologia. Nesse sentido, para uma renovação do ensino de ciências, segundo os pressupostos supracitados, seria mais centralizada na

1 CNE/CP 1/2002: Institui as Diretrizes Curriculares Nacionais para a Formação de Professores de Educação Básica, em nível superior, curso de licenciatura, de graduação plena, aprovada em 18/02/2002 e publicada no Diário Oficial da União, de 04 de março de 2002, na seção 1, p. 8. Essa formação deveria, segundo a Resolução CNE/CP 2, de 19 de fevereiro de 2002, publicada no mesmo DOU, p. 3, ser integralizada em, no mínimo 03 (três) anos letivos, tendo uma carga horária mínima de 2.800 horas.

2 CNE. Resolução CNE/CES 9/2002. Estabelece as Diretrizes Curriculares para os cursos de Bacharelado e Licenciatura em Física. Diário Oficial da União, Brasília, 26 de março de 2002. Seção 1, p. 12. 
forma de trabalho com o conteúdo, constatada por estratégias fixadas em uma reestruturação do trabalho pedagógico, pautada em uma renovação epistemológica na formação dos professores e de uma renovação didática de suas aulas, previstas em documentos institucionalizados pelo ministério da educação, os PCNs e o currículo do ensino básico do Estado de São Paulo, sendo este último, estabelecido entre 2008 e 2009. Em acordo com essas teses progressistas, segundo Cachapuz et al. (2005), os documentos institucionais, PCNs e currículo básico paulista consideram que as mudanças nas práticas de ensino dependem quase que exclusivamente de uma nova postura do professor em sala de aula, sendo apenas este item determinante para que os alunos sintam uma sólida coerência entre o falar e o fazer e possam se inserir plenamente no processo de ensino aprendizagem.

Os documentos publicados pelo ministério da educação e a secretaria estadual paulista visam ao docente a substituição de concepções de ensino informativo, isto é pautado em transmissão de informações, pelo ensino mais formativo, tomado a partir de novas concepções de práticas e estratégias metodológicas, menos centradas em "falas" e "apresentações de fórmulas", segundo Carvalho (2004), portanto, menos informativo, para Santos (1991), e se confirma na revisão de Carvalho e Vannucchi (1996) sobre as tendências em inovações curriculares de Física, associando as mudanças de estratégias de ensino, a partir do uso institucional de elementos de História e Filosofia da Ciência e por abordagens de enfoque tecnológico.

Acrescenta a presente análise que as contextualizações de conteúdos pelo uso de elementos de História e Filosofia da Ciência, conforme salienta Matthews (1995), nem sempre se encontram viáveis, dadas as dificuldades de acesso a materiais confiáveis e fontes disponibilizadas numa forma apropriada para o trabalho pedagógico, porém se torna essencial ressaltar a presença constante das temáticas de uso História e Filosofia da Ciência nos principais eventos da área de Ensino de Ciências e Ensino de Física, a saber, se exemplificam no Simpósio Nacional 
de Ensino de Física e o Encontro de Pesquisa em Ensino de Física que tem mostrado uma grande quantidade de relatos de contribuições dessas estratégias na atuação docente. Mathews (1995) ressalta estratégias de argumentação e organização dos conteúdos mais interessantes e significativos. Sobre este ponto, entretanto, sedimentam lacunas e falácias das quais pretende-se discutir na presente pesquisa. Em tal contexto, pergunta-se qual o papel do professor de Ciências dentro de uma educação que visa à formação de um cidadão com conhecimentos específicos, mas também críticos e formador de opinião? Os professores que estão sendo formados para atender às necessidades previstas em documentos oficiais, com os pressupostos construtivistas reflexivos no Ensino de Ciências, têm sucesso em investidas como cadernos curriculares do estado de São Paulo? Que fatores influenciam o desenvolvimento de uma atividade por parte do professor em sala de aula e quando eles realizam uma abordagem que visa uma formação diferenciada do aluno? Neste trabalho não se pretende dar respostas a todas essas perguntas e a outras que daí poderiam se originar, mas busca investigar uma parte dessas questões que se relaciona a inserção da história e filosofia da ciência no ensino de ciências e a formação docente para abordar tal perspectiva.

É sobre os elementos que definem a realidade, presente nos fundamentos das teses pós anos 1990, que se sedimenta a crítica a ser desenvolvida na pesquisa aqui formulada. É de considerar para isso, a princípio, como um ponto favorável de que se justificam tais teses, modificações nas estratégias de ensino, e que estas podem se mostrar melhores que abordagens tradicionalistas, tidas como essencialmente conteudistas, por apontar alguns dos seus problemas, basicamente em relação metodológica com os conteúdos. Assim apontam Villani (1984) e Camargo e Nardi (2004), pois os conteúdos se apresentam essencialmente ausentes de reflexões e discussões e seguem pautados em transmissões e reproduções de livros didáticos, por meio de textos e de fórmulas em uma mera repetição e memorização de cálculos. 
No entendimento dos autores da pesquisa, a definição da problemática formulada nesses ideários apresentam uma concepção sobre "realidade" que desconsidera questões básicas, por exemplo: Quem é o aluno de ensino médio? O que ele necessita aprender de conteúdos e qual o objetivo do ensino neste nível? Quem é o professor da Educação Básica? Como formar professores compromissados com posturas que favoreçam a renovação no ensino de ciências e matemática? Que devem saber e saber fazer profissionais com esse perfil? Indo um pouco além dessas questões centradas na formação docente, indagam os autores da pesquisa: como é engajar o aluno nos cursos de educação básica? Os alunos e os professores são alienados em seu contexto de realidade com os demais contextos da sociedade? A qualidade dos recursos acessíveis permite uma elevação da qualidade de ensino, tal como se reivindica nas teses progressistas, centradas na retórica sobre a qualidade da formação do professor? Existem oportunidades efetivas da inserção plena dos alunos e dos professores aos espaços produtivos, e de que contextualizam as ações sociais dos conteúdos de ensino, tal como se aplica no mundo do trabalho? Com base nessa problemática se expõem a crítica aos argumentos da concepção denominada por "professor reflexivo".

\section{Síntese de apontamentos para a confrontação teórica}

A partir da identificação dos apontamentos críticos, nas revisões de Giardinetto (2000a), Duarte (2000) e Facci (2004) sobre a eficácia do trabalho com aspectos meramente tomados pela relação direta $\mathrm{e}$ espontânea com o aluno, e bem como na relação dicotômica entre a forma e o conteúdo a ser trabalhado pelo docente, se faz uma análise bibliográfica comparativa, em dois momentos:

a) "aportes para a crítica aos pressupostos reflexivos", em que se faz apontamentos da confrontação teórica dos pressupostos que torna 0 professor o fator determinante na sala de aula, na relação entre o conteúdo e o aluno. 
b) "a crítica das práticas reflexivas a partir de pesquisas recentes" em que se apresentam resultados de uma amostra de 7 pesquisas sobre a implementação e as práticas docentes envolvendo o currículo paulista, e sobre as práticas formuladas para o professor, em sua atuação, certificando as objeções delimitadas na confrontação desses pressupostos.

As considerações para a formulação de uma crítica acerca dos apontamentos progressistas nas pesquisas que sugerem a centralidade da formação docente na relação entre aluno e conteúdo, segundo Nóvoa (1997), como cerne dos problemas no ensino, partem da prerrogativa da má qualidade dessa formação e ressaltam como determinante a atuação dos professores da educação básica, especialmente sobre aspectos didáticos e metodológicos. Assim não tem sido levados em conta alguns elementos externos de análise dessa realidade, segundo Vale (1998), síntese de múltiplas determinações, e é sobre esse dado que se pretende esmiuçar as bases pressupostas, partindo de uma verificação do currículo básico de ciências, pois quais seriam os motivadores de inserção do sujeito aos meios produtivos da sociedade? Neste sentido, muitos têm sidos os apelos aos professores atuantes nas salas de aula, para que façam uma reformulação de estratégias, metodologias, mas pouco se fala sobre mudanças nos aspectos curriculares, associados aos conteúdos e que estes possam ser trabalhados de outras formas em sala de aula. As pesquisas recentes, denominadas progressistas, objetivamente, seguem pela tendência de fragilizar o trabalho didático e metodológico, geralmente tendo por fundamento teorias denominadas "construtivismo humano". Mintzes et al. (1998) fazem a crítica dos cursos atuais de licenciatura e os de formação pedagógica em educação básica para o ensino de ciências, em se considerando que esses cursos formam mal os seus professores e tendo como justificativa o fato de que esses cursos não tem se ajustado aos aspectos da realidade do aluno e nem das condições plenas de aprendizagem. 
Seguindo as teses de fundamento construtivista humano, para Duarte (2001), o professor teria em suas mãos os elementos essenciais e eficazes, ou seja, necessários e suficientes para uma mudança qualitativa sobre o modo de trabalho na sua relação com o aluno e o conhecimento a ser desenvolvido. As modificações nos cursos de licenciatura, iniciadas com as resoluções do CNE de 2002, serviram de base para a reestruturação desses cursos, dado evidenciado nas mudanças que se desencadearam nos anos seguintes como no que diz respeito à aquisição de condições para que os cursos de formação docente atendam às reivindicações propostas, tornando o trabalho do professor menos tradicionalista, isto é, menos pautado em "falas e escrita de regrinhas para decoreba", e sendo mais adaptado aos pressupostos dominantes nas últimas décadas. Confirmam Carraro e Andrade (2009) e Facci et al. (2010), a concepção de professor reflexivo de Donald A. Schön e as bases teóricas de Philippe Perrenoud têm servido de fundamento para a centralidade da crítica sobre os cursos de formação docente, inseridos nos documentos oficiais, em Brasil (2008), na forma de orientações curriculares, e igualmente sob esse ideário, o currículo paulista, conforme Almeida Neto e Ciampi (2015). Em ambos exemplos, reproduz-se a tese da centralidade da figura do professor, legitimada quase exclusivamente como um determinante do resultado do ensino. Segundo essas perspectivas, seria suficiente tomar como modelo de um novo professor, "reflexivo", formado por um curso reestruturado, segundo pressupostos menos tradicionalistas, para se alcançar a qualidade de ensino, assegurada por evidências idealizadas em documentos, cujas orientações servem de "receituário de métodos" para concretização da nova realidade do ensino básico.

Os pressupostos desses documentos oficiais devem ser considerados ineficazes, para Duarte (2001), na medida em que se desconsidera aspectos cruciais da realidade, a saber, as condições 
institucionais da escola e das possibilidades de acesso aos meios produtivos, ao invés disso, pressupõe-se apenas a relação direta com o conhecimento. A formulação da crítica sobre o ideário construtivista, conforme Giardinetto (2000) e Vale (1998), se firma no reducionismo da noção de realidade, menosprezada em suas múltiplas determinações, entre elas a forma que a vida se organiza em estruturas. Portanto, conforme Giardinetto (2000), propõe-se analisar as contraposições a esses argumentos propostos para resultados de práticas, reducionistas, pois pautadas na cisão entre o indivíduo e as estruturas sociais, dicotomizadas, fragmentadas nas suas relações, fato que se confirma nos dados coletados no item a seguir e justifica as tendências recentes, pós tradicionalistas, pois verificando as lacunas deixadas em segundo plano, deixam algumas possíveis intenções subjacentes ao uso desses referenciais de cenário acadêmico educacional e na educação básica em ciências das últimas décadas.

Portanto, a questão formulada neste excerto pretende apresentar dados coletados em pesquisas recentes, sobre a lacuna existente no ideário reflexivo para reformulação da atuação docente, pois, essa visão escamoteia aspectos, a saber, sobre a existência de materiais disponíveis, como dos livros didáticos, e se estes apresentam conteúdos com mais criticidade em relação ao mundo, e ainda, para Giardinetto (2000), se a disposição da estrutura regimental dos cursos de educação básica existente tem garantido as condições mínimas para uma ascensão social em despertar uma consciência crítica e reflexiva do alunado, ou então, se estes dois últimos aspectos dependem unicamente do perfil de professor reflexivo formado em um curso apropriado. 


\section{Aportes da crítica aos pressupostos reflexivos}

Realizando um breve esboço de revisão sobre as concepções existentes na estrutura dos cursos da educação básica, a grade curricular das disciplinas de ciências segue as normas publicadas nos PCN(s), PCN+ e o PCNEM, conforme Brasil (2008), iniciados por teorias defendidas na segunda metade dos anos 1990, segundo Duarte (2001) e tem por fundamento, conforme Facci (2004), as pesquisas progressistas de cunho reflexiva, entretanto, pautadas quase que exclusivamente na legitimidade da atuação do professor, um determinante que por si é capaz de deter os meios de transformação da realidade de ensino, abordando os conteúdos de forma mais ajustada a este fim, partindo para uma mudança de apresentação, menos linear, para uma melhor contextualização de conteúdo, geralmente pelo uso da história (HC) e filosofia da ciência (HFC).

Salientam as orientações curriculares que os aspectos seculares ao docente, como materiais didáticos e outros textos de apoio, nem sempre se encontram apropriados para abordagens reflexivas e contextualizadas com esses propósitos:

\footnotetext{
Muitas tentativas de mudança nas práticas educacionais esbarram na falta de material didático. Historicamente a escola se apoia no livro didático, que nem sempre está presente na escola pública. Outros materiais didáticos para promover a melhoria de ensino são deficitários. Existem livros paradidáticos que seriam de grande ajuda na atualização e revisão do professor na sala de aula, além de outras fontes de informação, via revistas especializadas e internet [...]. (BRASIL 2008, p. 56).
}

Outro fator a ser questionado na pesquisa aqui moldada é sobre aspectos regimentais do formato dos cursos básicos, pois muitas vezes o estudante não se encontra respaldado pelas políticas públicas, para que tenha motivação de estudar e de realizar curso superior, ou mesmo um curso técnico, apesar de ser um item essencial para mudanças na legislação, iniciadas em 1996, que estabelece: 


\begin{abstract}
Art. 350 ensino médio, etapa final da educação básica, com duração mínima de três anos, terá como finalidades: 1 - consolidação e aprofundamento dos conhecimentos adquiridos no ensino fundamental; 2 - a preparação básica para o trabalho e a cidadania do educando, para continuar aprendendo, de modo a ser capaz de se adaptar com flexibilidade a novas condições de ocupação ou aperfeiçoamento posteriores; 3 - o aprimoramento do educando como pessoa humana, incluído a formação ética e o desenvolvimento da autonomia intelectual e do pensamento crítico; 4 - a compreensão dos fundamentos científico-tecnológicos dos processos produtivos, relacionando a teoria com a prática, no ensino de cada disciplina. (BRASIL, 2008, p. 33).
\end{abstract}

O docente vinculado ao ensino básico teria, a partir da legislação, a prerrogativa de reunir todos os elementos necessários para a garantia de aprendizagem conceitual em ciências, contextualizada com a realidade do alunado, condições necessárias e apropriada aos aspectos de autonomia e de amplo acesso aos meios sociais de que o conteúdo curricular está inserido, em propiciar acesso nas relações de trabalho produtivo e de outros itens institucionais elencados, como das produções intelectuais e culturais, o que justifica as reestruturações dos cursos de licenciatura, a partir do CNE de 2002, estes dois fatores, segundo Fávero et al. (2013), têm servido de base para as pesquisas atuais, referentes ao pressupostos e às práticas de ensino, a partir dos discursos docentes, iniciadas na década de 1990. O contraposto desse argumento da concepção de professor reflexivo está presente na análise dos pressupostos acerca dessa prerrogativa, como apresenta Moraes Júnior (2011), e se considera no bojo dos aportes teóricos e metodológicos desenvolvidos na pesquisa aqui formulada, pois nas referências citadas, se desconsidera aspectos estruturais da história da consolidação da profissão docente, tais aspectos são externos ao relacionamento entre professor e aluno na criação das condições propicias de aquisição de conhecimento e de promoção da autonomia intelectual. 
Em relação à formação da personalidade, vemos que as condições objetivas da nossa sociedade estão promovendo o surgimento de determinadas características psicológicas que só podem ser compreendidas se considerarmos as demandas do contexto social em que os indivíduos vivem. (FACCI, 2010 apud MORAES JÚNIOR 2011, p. 4).

Em suma, a singularidade da pessoa, seja do professor formado, ou de seus alunos individualmente, constituem partes integrantes de um todo que se molda estruturalmente, e a partir do modo de produção e de organização das relações sociais estabelecidas no momento histórico que se apresenta em questão, segundo a autora "a questão nuclear diz respeito aos modos de produção dos sujeitos na sociedade contemporânea" (MORAES JÚNIOR, 2011, p. 215). A concepção da realidade apresentada na abordagem reflexiva de que se amparam as pesquisas sobre a formação docente tem sido confrontada no campo da psicologia e da sociologia, essencialmente sobre as condições de aprendizagem e sobre meios objetivos de acesso aos aspectos de autonomia e de inserção social, sobretudo, na perspectiva capitalista e em que a divisão de classes sociais constituem aspectos abstratos em que se formam as estruturas da realidade, não são muros físicos mas se encontram nas divisões da sociedade de classe, na sua relação com o capital.

Segundo Facci (2004), existe um fator abstrato presente em um olhar histórico e social sobre a realidade educacional, e se torna modelador do próprio conceito de reflexão, dada a existência da ideologia ${ }^{3}$ e de meios de controle de classes sociais, sobre a perspectiva da análise sociológica de Marx e Engels, à medida que o ser humano se modela na sua forma de agir e de pensar sobre a realidade da qual faz parte, por meio das relações

\footnotetext{
3 A ideologia de classes constitui uma matriz de fundamento na relação entre o dominante e o dominado. Impõem ao sujeito algumas barreiras, de modo abstrato, um reducionismo definido por Facci (2004) como um condicionante para apropriação do conhecimento, pois está condicionado ao seu uso efetivo, como instrumento de transformação da realidade, seria portanto, parcial e fragmentado a forma como se encarra a análise, centrada na atividade em sala de aula, sem se conectar com as instituições produtivas que se aplicam esses conhecimentos curriculares.
} 
sociais que se estabelece, o mesmo acontece na escola, estas reflexões segundo a autora estão socialmente condicionadas pelas limitações que se processam no meio.

Esse reducionismo encerraria a prática reflexiva do professor dentro do campo de sua prática pedagógica. Nesse sentido, o professor deveria pensar apenas os meios de superar os problemas cotidianos, e imediatos, surgidos e vividos na escola, reduzindo, assim, o exercício reflexivo, ao fazer técnico, ao praticismo das questões imediatas. (MORAES JÚNIOR, 2011, p. 220).

Em suma, a existência das barreiras não se concentram essencialmente na forma que se relaciona com o conhecimento, e mais propriamente nas estruturas sociais que não são apenas institucionais, devem ser vistas como abstrações que dividem as relações dos indivíduos na relação entre meio e que não são consideradas em Perrenoud, conferindo uma redução, meramente no campo da prática pedagógica, desconectando as relações existentes no domínio histórico e social que estabelece os modos de agir e de pensar, bem como em organizar a produção enquanto determinantes externos, condicionado socialmente por abstrações estruturais visceralmente presentes na constituição da realidade da qual faz parte o processo pedagógico, a tal endosso se constata, por meio da inserção dos termos que estão presentes nos $\operatorname{PCN}(\mathrm{s})$, de que fazem parte da competitividade, estabelecidas nas leis de mercado, se fazem presentes na construção das teorias de formação básica, ora examinada.

[...] essa relação entre a atitude reflexiva do professor, na perspectiva da confecção das competências necessária para o exercício docente, gera uma espécie de competitividade de mercado que o capital forja como protótipo para qualquer profissionalidade. Acrescenta, ainda, que a proposição das competências estabelece um íntimo vínculo com as "exigências da globalização, do mundo do desemprego, do ideário liberal" [...] o capital, na forma como os preceitos neoliberais estão aglutinados ao mercado de trabalho, requer um trabalhador polivalente, com capacidade de adaptar-se a várias frentes de trabalho, com diversas competências para dar conta de atender às necessidades postas pelo espírito mercantil, salienta a autora que a formação dada ao profissional professor 


\begin{abstract}
situa-se, de certo modo, dentro dessa lógica do mercado. Lembra, ademais, que autores do timbre de Perrenoud (1999), por exemplo, legitimam tal investida quando afirmam uma espécie de reducionismo da educação, na expectativa da confecção das competências, à vida cotidiana. (MORAES JÚNIOR, 2011, p. 220).
\end{abstract}

Os aportes teóricos e metodológicos sobre a leitura dos referenciais das pesquisas sobre a formação do professor têm sido o primado das teorias sociológicas neoliberais, suscitando reflexões estanques das determinantes estruturais da história. A própria abordagem histórica, nem sempre segue vinculada com as determinantes externas ao processo de elaboração do conhecimento científico. Uma abordagem crítica da história deve considerar a organização social e produtiva daquele momento em contexto, de que um dado teórico curricular se institucionaliza. Como visto em Meis e Carmo (2004), encontra-se o conteúdo básico tratado em uma pesquisa sociológica da ciência e, em sua estrutura, apresenta aspectos sociais e culturais, vinculados aos trabalhos dos cientistas, durante etapas de formulação das teorias, aborda-se temas da física e da química no século XIX, suas intenções e questões históricas relacionadas, fator que muitos autores de livros didáticos não têm levado em conta como verifica Christófalo et al. (2016), em uma visão sobre as estratégias necessárias aos autores na sua relação com o conteúdo. Indaga oportunamente este item, se o professor reflexivo poderia ter meios de levar seus alunos até um ambiente produtivo e em que estes conhecimentos se tornam instrumentos efetivos de transformação dos recursos naturais?

Conforme a contradição aqui exposta, passa-se ao desdobramento da questão da pesquisa aqui formulada, pois apresentam-se resultados das inconsistências diagnosticas na revisão literária, o que serve da fundamento para crítica ao ideário de professor reflexivo, que basicamente é entendido como não estando condicionado por uma realidade de ensino, sobre uma mera visão dos discursos dos professores em suas práticas. Os professores, detentores da prerrogativa do trabalho didático e pedagógico na sala de aula, estão inseridos em uma realidade social mais ampla e 
cujas determinações se fazem presentes mais externamente, por isso, se torna necessário um olhar sobre essas estruturas, repensando os aspectos metodológicos utilizados para a coleta de dados qualitativos, formulando uma crítica das teorias reflexivas a partir de resultados levantados nas pesquisas recentes sobre as práticas da atuação docente.

\section{A crítica das práticas reflexivas a partir de pesquisas recentes}

A identificação de dados coletados em pesquisas sobre aspectos das práticas desenvolvidas a partir dos pressupostos de ideário reflexivo tem se identificado em convergência aos argumentos do exposto crítico sobre seus pressupostos. O caso de maior aplicabilidade de análise pode ser visto na implementação do currículo oficial de ensino básico que tem por referência as matrizes de competências e as bases teóricas centradas na atuação do professor como agente regulador das situações de aprendizagens, instituído em 2008, SEE-SP, sob a coordenação de Maria Inês Fini. Foi oficializado em meados de 2010, reafirmando fundamentos centrados na estratégia docente, fomentando receitas práticas para tais atuações, reivindicando leituras e contextos históricos.

Segundo Gonzales (2012, p. 35, grifo do autor), "na Nova Proposta Curricular de São Paulo o professor é limitado à função de executor, não tendo possibilidade de escolha dos conteúdos propostos". O ideário neoliberal se verifica na ação centrada na figura do professor, desenvolvedor das estratégias, visando padronizar ações por um receituário, dando um passo além das orientações aos professores fornecidas pelo ministério da educação. Apontam sobre este fato, resultados de pesquisas sobre a eficácia dessa proposta, que constam no Quadro 1. 


\section{Quadro 1 - Resultados encontrados nas pesquisas sobre práticas docentes, atuantes na SEESP}

\section{Adequação das condições de trabalho: Resultados práticos segundo docentes: \\ "A proposta curricular está fora da realidade" "não tem sentido prático para o aluno algumas (CATANZARO, 2012, p. 95). coisas são difíceis e não existe tempo hábil para desenvolver esses itens complexos, além disso, algumas coisas se encontram desconexas" (CANTAZARO, 2012, p. 96), cerca de cinco docentes entrevistados.}

"A concretização da reforma curricular "existem ações externas que antecedem a uma pressupõem uma política de capacitação mudança de abordagem, menos conteudista e docente diferenciada, ou seja, uma mudança de mais pautada na relação com o conhecimento" mentalidade para que os argumentos (DIAS; AMARAL, 2012 p.632), cerca de quatro pedagógicos não permaneçam na esfera do decentes entrevistados.

discurso. Nos cursos de formação de professores é preciso que os mesmos substituam a lógica do saber muito pela possibilidade de se lidar crítica e significativamente com o conhecimento" (DIAS; AMARAL, 2012, p. 632).

"falta de livros complementares e Parte dos docentes não utilizam o material, e os complexidade de conteúdos e linguagem" que utilizam reconhecem que o material contém (CARVALHO, 2015, p. 19219). erros e inadequações, de acordo com a realidade do aluno" (CARVALHO, 2012, p. 19250), envolve cerca de cinquenta docentes.

"apresenta atualidade e conformidade com "não respeita diversidades e regionalidades4" pesquisas em educação" (SILVANA et al., 2017, (SILVANA et al., 2017, p. 370) não envolve p. 370). docentes.

"todos os docentes consideram os conteúdos "maior parte dos professores tiveram desconexos, fragmentados, carecendo de dificuldades em reconhecer que o aluno deve bases e de explicações conceituais" formular respostas nas situações de (CARVALHO; NARDI, 2016, p. 126). aprendizagens, contudo se reconhece uma superficialidade da produção desses cadernos, pois resultam de uma pesquisa momentânea de universidade, por isso, desconsidera a realidade do aluno, pois, o material não proporciona uma formação crítica dos temas abordados" a pesquisa analisa cerca de oito docentes (CARVALHO; NARDI, 2016, p. 127).

Fonte: Elaborado pelos autores, conforme Carvalho; Nardi (2016).

${ }^{4}$ Este item foi revisto em 2015 pelo Ministério da Educação 


\section{Considerações finais}

Existe uma contradição na realidade de implementação da proposta em boa parte dos resultados obtidos nas pesquisas envolvendo as práticas docentes. Na maior parte, a análise de implementação da proposta para contextualização do ensino a partir de fundamentos históricos, bem como a partir da formação do cidadão crítico, converge para uma retratação da insuficiência da formulação da metodologia que, em alguns casos, tenta ser justificada por uma má formulação dos cadernos, em desacordo com a realidade do aluno. Porém segue uma base de fundamento que se confirma em Carvalho e Nardi (2016) sobre o aluno, uma situação de aprendizagem, de formular as respostas, ao invés do docente as explicitar em falas e escritas na lousa.

Outro aspecto que se destaca, conforme Mininel et al. (2017), é a unanimidade em que os docentes afirmam desse material estar desconexo e em desacordo com a realidade do aluno, distante das condições sociais e motivacionais, não se vê sentido prático, além da complexidade e dificuldade de compreensão dos assuntos, da maneira como foram organizados, apesar de partir-se de ideias atuais da pesquisa.

Como um todo, as sete pesquisas mostraram que esse modelo construtivista de ação docente, centrado em estratégias que partem da iniciativa do professor, como propiciador das situações de aprendizagem, não tem surtido os resultados que se esperavam. Os resultados têm sido parciais e inconstantes, segundo Giardinetto (2000), dado que não são inseridos aspectos, nesses roteiros de atividades, da sincronia da realidade social e das formas necessárias para se integrar o aluno ao contexto efetivo que esse conteúdo se aplica no mundo do trabalho-produtivo, convergindo com as críticas sobre o conceito firmado entre o professor, o aluno e o conhecimento, nos pressupostos de professor reflexivo, segundo Moraes Júnior (2011). 
Em suma, tanto as pesquisas que criticam a implementação da proposta curricular quanto os fundamentos se referem aos pressupostos construtivistas e de centralidade na prática docente reflexiva, o que expõem a contradição inicialmente formulada por Facci (2004), e confere uma ausência de elementos de análise sobre a relação entre o conhecimento e o contexto de aprendizagem e de motivação. Segundo esses pressupostos, a forma como se estrutura a educação básica é estanque e fragmentária.

\section{Referências}

ALMEIDA NETO, Antonio S. de A.; CAMPI, Helenice. História a ser ensinada em São Paulo. Educação em Revista, Belo Horizonte, v..31, n.1, pp.195-221, Jan./Mar. 2015.

BRASIL. Ciências da natureza, matemática e suas tecnologias. Brasília, DF: Ministério da Educação, 2008.

CACHAPUZ, António et al. A necessária renovação do ensino das ciências. São Paulo: Cortez, 2005.

CAMARGO, Sergio et al. A reestruturação do projeto pedagógico de um curso de licenciatura em física de uma universidade pública: contribuições de licenciandos ao projeto. Revista Ensaio, Belo Horizonte, v.14, n.3, p. 217-235, 2012.

CAMARGO, Sergio; NARDI, Roberto. Prática de Ensino de Física: marcas de referenciais teóricos no discurso de licenciandos. Revista de Enseñanza de la Física. Universidad Nacional Rosário, Rosário, v. 17, n. 1, p. 23-42, 2004.

CARRARO Patrícia R.; ANDRADE, Antonio dos SANTOS. Concepções docentes sobre o construtivismo e sua implantação na rede estadual de ensino fundamental. Revista Semestral da Associação Brasileira de Psicologia Escolar e Educacional (ABRAPEE), v. 13, n. 2, p. 261-268, jul./dez. 2009.

CARVALHO, Anna M. P. Ensino de ciências: Unindo a Pesquisa e a Prática São Paulo Thompson Learning, 2004.

CARVALHO, Anna M. P.; GIL-PEREZ, Daniel. Formação de professores de Ciências: tendências e inovações. São Paulo: Cortez, 2009.

CARVALHO, Anna M. P.; VANNUCCHI, Andréa. O Currículo de Física Inovações e Tendências nos anos 90. Investigações no Ensino de Ciências, v. 1, n.1, pp. 3-19, 1996.

CHRISTÓFALO, Airton A. et al. Erros e distorções, históricas e conceituais nos livros didáticos de física. É preciso confrontá-las: Um estudo de caso. Revista Didática Sistêmica, Rio Grande, RS, v.18, n.1, p.93-108, 2016. 
DUARTE, Newton. A individualidade para si: contribuições a uma teoria histórico-social da formação do indivíduo. Campinas: Autores Associados, 2000. DUARTE, Newton. Educação escolar, teoria do cotidiano e a escola de Vigotski. Campinas: Autores Associados, 2001.

FACCI, Marilda G. D. Valorização ou esvaziamento do trabalho do professor: um estudo crítico comparativo da teoria do professor reflexivo, do construtivismo e da psicologia vigotskiana. Campinas: Autores associados, 2004.

FACCI, Marilda G.D. et.al. O trabalho e a formação do professor nos anais da ANPED: uma análise a partir da psicologia histórico-cultural. Revista Intermeio. Programa de Pós-Graduação em Educação, Campo Grande, MS, v.16, n.31, p.216-237, jan./jun. 2010.

FÁVERO, Altair A. et.al. A formação de professores reflexivos: a docência como processo de investigação. Educação, UFRS, Santa Maria, RS, v. 38, n. 2, p. 277288, maio/ago. 2013.

GIARDINETTO, José R.B. Reflexões ante as concepções de "espontaneidade" e de "eficácia" do saber matemático cotidiano presente em algumas pesquisas em Educação Matemática. Educação Matemática Pesquisa, PUC/SP, São Paulo, v. 2, n. 2, pp. 35-50, 2000.

GONZALES, Keila P. Nova proposta curricular do estado de São Paulo: inovações ou continuidades no ensino de história. Interfaces da Educação. Paranaíba, v.2, n.6, p.29-36, 2012.

MEIS, Leopoldo de; CARMO, Diucenio A. R. A respiração e a 1a lei da termodinâmica. Rio de Janeiro: Editora da UFRJRJ, 2004.

MATTHEWS, Michael R. História e Filosofia da Ciência: Tendência atual de reaproximação. Caderno Catarinense de Ensino de Física, UFSC, Florianópolis, SC, v. 12, n. 3, p.164-214, dez. 1995.

MININEL, Silvana M. X. Considerações de professores em relação à implantação da Proposta Curricular de Química do Estado de São Paulo. Química Nova na Escola, São Paulo/SP, v. 39, n. 4, p. 368-372, nov. 2017.

MINTZES, Joel J. et al. Ensinando Ciências para a Compreensão. Lisboa: Plátano, 1998.

MORAES JÚNIOR, José de A. Para uma crítica dos discursos da identidade reflexiva. Educação em Perspectiva, Viçosa, MG, v. 2, n. 2, p. 211-222, jul./dez. 2011

NÓVOA, António. Formação de professores e profissão docente. In: NÓVOA, A. (Org.). Os professores e a sua formação. Lisboa: Publicações Dom Quixote, 1997.

SANTOS, Maria Eduarda M. Mudança conceitual em sala de Aula: em desafio epistemologicamente bem fundamentado. Lisboa: Livros Horizonte, 1991.

VALE, José M. F. Educação Científica e Sociedade: In: NARDI, Roberto (Org.). Questões Atuais no Ensino de Ciências. São Paulo: Escrituras, 1998. 
VILLANI, Alberto. Reflexões sobre o ensino de Física no Brasil: práticas, conteúdos e pressupostos. Revista Brasileira de Ensino de Física, v. 6, n. 2, p. 76-95, dez.1984. 